\title{
Tritiated hay and chromium-mordanted neutral- detergent fibre as particulate markers for digesta kinetics in the reticulo-rumen
}

\author{
J. VAN BRUCHEM, F. KAMPHUIS, I. JANSSEN, S. C. W. LAMMERS- \\ WIENHOVEN, G. A. BANGMA \& J. VAN DEN HOEK
}

Department of Animal Physiology, Wageningen Agricultural University, Haarweg 10, NL 6709 PJ Wageningen, Netherlands

Received 28 September 1988; accepted 5 September 1989

\begin{abstract}
In sheep fed on wilted grass silage, passage of the reticulo-ruminal particulate phase to the lower gut was estimated with chromium-mordanted neutral-detergent fibre (CrNDF) and tritium-labelled hay as markers, the latter subject to both passage and reticulo-ruminal degradation. Fractional passage rates $\left(k_{\mathrm{p}}\right)$ were deduced from the faecal marker excretion curves. For CrNDF and tritium, $k_{\mathrm{p}}$ averaged 2.44 (SEM 0.19) and 3.38 (SEM 0.20) \% $\mathrm{h}^{-1}$, respectively. The difference (tested with paired Student $t)$ was significant $(P<0.01)$.
\end{abstract}

Keywords: ruminants, feed intake, passage rate, cell wall constituents, particle pools, rumination

\section{Introduction}

Clearence of feed particles from the reticulo-rumen depends on at least two processes, physical and fermentative breakdown of feed particles and passage of small undigested particles through the reticulo-omasal orifice. Feed particles are concomitantly subject to both breakdown and passage. Initially breakdown as achieved by microbial degradation and physical breakdown by rumination are predominant.

Whether particles are able to leave the reticulo-rumen depends on their size and specific gravity. In sheep the size should be such that they can easily pass a sieve with a pore size of $0.89 \mathrm{~mm}$, the so-called critical particle size (Kennedy \& Poppi, 1984). The length of such non-spherical oblong particles is 4-5 times the pore size. Particles can only pass to the omasum after arrival in the ventral part of the reticulum. In the course of the fermentation process in the reticulo-rumen, the specific gravity of the particles increases. Feed particles are propagated gradually from the dorsal rumen sac via the ventral rumen sac into the reticulum, from where they are propulsed into the omasum by reticular contractions. Specific gravity of the parti- 
cles increases, probably primarily because of a gradual decrease of fermentation due to substrate limitation, coinciding with a decrease in gas production (Evans et al., 1973). According to Welch (1986), particles with specific gravity between 1.17 and $1.42 \mathrm{~kg} \mathrm{dm}^{-3}$ pass most rapidly from the reticulo-rumen. The mechanisms, by which particles of smaller size and higher density are selected for passage, have not clearly been identified but are thought to include the sieving or 'filter-bed' effect of the rumen digesta mass (Faichney, 1986). Sutherland (1987) showed that concomitantly with the migration of particles from the dorsal to the ventral rumen sac and finally into the reticulum, mean particle size decreases and the ratio of buoyant to sedimenting particles decreases.

For the estimation of the kinetics of passage of undegraded feed particles, various markers are available. Among these, chromium-mordanted neutral-detergent fibre (CrNDF) and ruthenium phenanthroline ( $\mathrm{Ru}-\mathrm{P})$ are frequently applied. Both markers, although generally accepted as particulate markers, have disadvantages. The $\mathrm{Cr}$-mordanted particles do not participate in the fermentation process and can by no means represent the bigger particles, whereas with Ru-P associated particles rapid migration between available binding sites occurs (Faichney \& Griffiths, 1978).

This paper describes the oral application of tritium-labelled hay as a marker. With respect to psysical and microbial degradation and finally passage, the indigestible organically bound tritium fraction of the hay may possibly be regarded as more representative for the behaviour of particles in the reticulo-rumen. However, markers applied in digestion trials have to meet the criterion of indigestibility. The limitations and advantages of tritium-labelled hay, which after all does not meet the criterion of indigestibility, as a marker for rumen kinetics are discussed with the aim to highlight the validity of reticulo-rumen particle passage rates as determined with indigestible small-particle markers such as CrNDF.

\section{Materials and methods}

Third cut wilted grass was ensiled and fed to four Texel wethers, provided with cannulas in the dorsal rumen sac. The silage was supplied at two levels of intake, two wethers were fed $883 \mathrm{~g} \mathrm{DM}$ and the other two $1248 \mathrm{~g} \mathrm{DM}$ per day. The silage was equivalent to the G2 silage supplied by Bosch et al. (1988). In that paper details on silage composition are given. Feed was supplied in 6 equal portions, with intervals of $4 \mathrm{~h}$. The sheep were kept in metabolism cages during the experiments, where they had free access to water.

Passage of feed particles from the reticulo-rumen to the omasum was determined with CrNDF $(10 \mathrm{~g}, 0.2-1.0 \mathrm{~mm}$, ca $5 \% \mathrm{Cr})$ and with tritium-labelled hay $(10 \mathrm{~g}, 2000$ pCi $\mathrm{g}^{-1}$. CrNDF was prepared as described by Uden et al. (1980). The tritiumlabelled hay was obtained by artificially drying $\left(70^{\circ} \mathrm{C}\right)$ of young grass sprayed at regular intervals with tritiated water as described by van den Hoek et al. (1985). On a dry matter basis, crude protein and crude fibre contents were $28.2 \%$ and $17.6 \%$, respectively.

At the onset of the experiment, CrNDF was introduced through a hard pvc tube 
(internal diameter of $1.5 \mathrm{~cm}$ ) into the ventral rumen sac via the rumen cannula whereas the tritium-labelled hay was ingested orally. Faeces were subsequently collected in individual portions during $120 \mathrm{~h}$. The $3 \mathrm{rd}$, 4th and 5 th nights were omitted from 8:00 h p.m. till 8:00 h a.m. In each sheep, the experiment was carried out twice.

Faeces were dried at $70{ }^{\circ} \mathrm{C}$, subsequently ground ( $1 \mathrm{~mm}$ sieve) and stored for analyses. Chromium was determined according to Bosch et al. (1988), and tritium as described by van den Hoek et al. (1983).

The faecal excretion curves were analysed mathematically according to the twocompartment model of Grovum \& Williams (1973).

$$
C_{t}=A_{0}\left[\exp \left\{-k_{1}(t-T T)-\exp \left\{-k_{2}(t T T)\right\}\right]\right.
$$

where:

$k_{1}=$ rate constant reticulo-rumen $\left(\mathrm{h}^{-1}\right)$

$k_{2}=$ rate constant caecum-colon $\left(\mathrm{h}^{-1}\right)$

$t \quad=$ time (h)

$T T=$ transit time $(\mathrm{h})$

$A_{0} \quad=$ conversion factor

$C_{t}=$ marker concentration at time $t$

Initially $k_{1}$ and $k_{2}$ were determined by linear regression according to the method described by Grovum \& Williams (1973). Subsequently, these values were optimized with a BMDP (Anonymous, 1983) non-linear regression program. The fit of the resulting curves was judged by eye and based on the residual standard deviation.

\section{Results and discussion}

In Figure 1, two representative examples A and B of faecal excretion curves of chromium and of tritium are given.

First appearance of the markers in the faeces, calculated as total transit time $(T T)$, was 20.2 (SEM 1.35) and 20.6 (SEM 0.85) h after marker application for chromium and tritium respectively, values which do not differ significantly.

According to Ulyatt et al. (1986), chewing during eating causes approximately $50 \%$ of physical breakdown of large feed particles (LP) into small particles (SP) below the critical particle size, defined as the nominal sieve aperture retaining the top $5 \%$ of faecal particulate matter, and according to Kennedy \& Poppi (1984) 0.89 $\mathrm{mm}$ for sheep. This figure is presumably related to the type of diet. Physical comminution of the residual part of the large particles occurs gradually by rumination. However, upon ingestion, a significant part of the tritium-labelled hay arrives directly in the SP pool. This probably explains why no difference in $T T$ appeared between both markers.

With the tritium-labelled hay entering the rumen for a significant part as large particles, to the two-compartment model as defined by Grovum \& Williams (1973), a third compartment is added and as a result a more gradually progressing (lower 

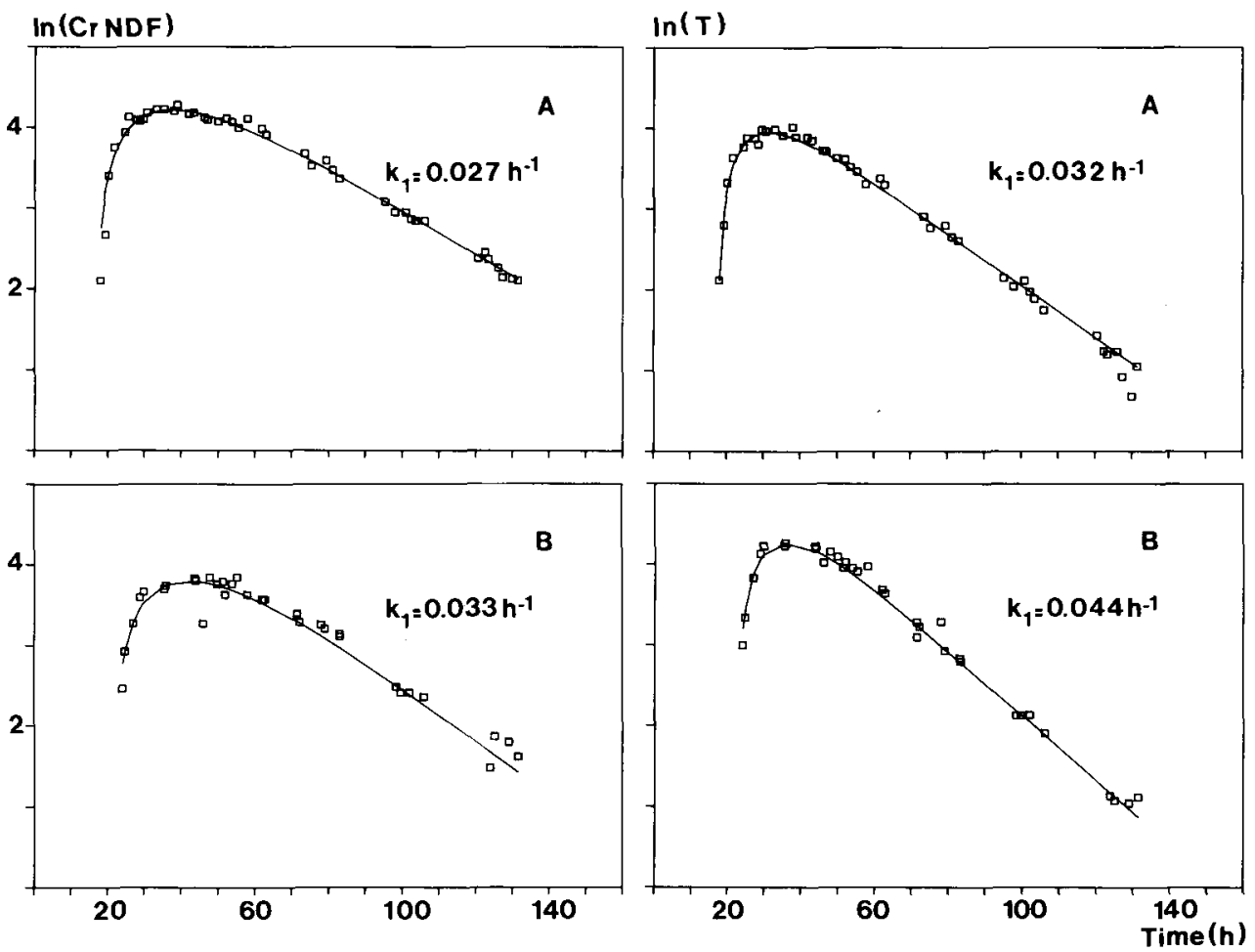

Fig. 1a (left). Two representative faecal excretion curves (A and B) of CrNDF, plotted semi-logarithmicly (arbitrary units) against time elapsed since marker application into the reticulo-rumen.

Fig. 1b (right). Two representative faecal excretion curves (A and B) of tritium, plotted semi-logarithmicly (arbitrary units) against time elapsed since marker application into the reticulo-rumen.

$k_{2}$ ) faecal excretion curve would be expected. However, this is not confirmed by the actual results. The $k_{2}$ values obtained averaged 5.5 (SEM 0.54) and 7.6 (SEM $0.97) \% \mathrm{~h}^{-1}$ for chromium and tritium, respectively. It was surprising that for both CrNDF and tritium the $k_{2}$ values were that low, and that for tritium the rising part of the excretion curve was the steepest part $(P<0.01$, paired Student's $t)$. The first observation is presumably related to the low level of feed intake. The latter finding could possibly be explained by the fact that at the time $k_{2}$ is determined (faecal excretion curve $20-40 \mathrm{~h}$ after marker administration of tritium hind gut fermentation has probably still been substantial.

In Figure 2, the $k_{1}\left(k_{\mathrm{p}}\right)$ values, as deduced from the descending parts of the faecal excretion curves of chromium and tritium, are summarized. The average $k_{\mathrm{p}}-$ values were 2.44 (SEM 0.19) and 3.38 (SEM 0.20) \% $\mathrm{h}^{-1}$ for chromium and tritium, respectively, and they differed significantly $(P<0.01)$; paired Student's $t)$.

In contrast to CrNDF, clearance of tritium-labelled particles from the reticulorumen is not confined to passage to the lower gut only. A consistent part of tritium 


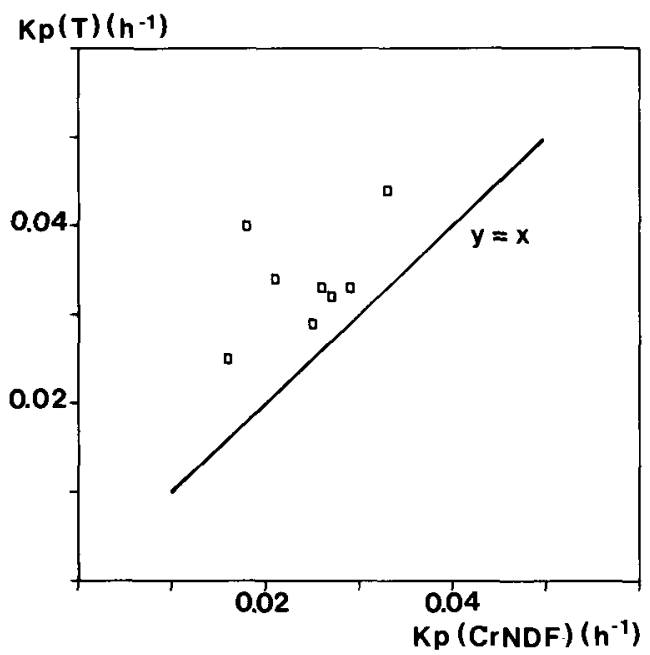

Fig. 2. Fractional rates of passage $\left(k_{\mathrm{p}}\right)$ of tritium from the reticulo-rumen as related to those of CrNDF.

clearance from the reticulo-rumen may be ascribed to microbial degradation of the tritium-labelled hay, and the question might be raised whether this could explain the higher $k_{1}$ value. Partly the organically bound tritium is incorporated into volatile fatty acids, subsequently absorbed from the reticulo-rumen and lower gut, or eructated with methane. Another part will be incorporated into microbial biomass, leaving the reticulo-rumen for the major part attached to small particles. Microbial biomass digestibility in the lower gut was shown to be high (van Bruchem et al., 1987), so that only a fraction of presumably less than $10 \%$ will be excreted with the faeces.

However, the gradual decline of tritium activity in the reticulo-ruminal pool of small particles by both microbial degradation and passage of undegraded particles to the lower gut may bias the conclusion that the slope of the descending part of the tritium excretion curve represents passage of tritium-labelled particles from the reticulo-rumen only. To quantify a possible effect of degradation on $k_{1}$, a twocompartmental model was simulated comprising reticulo-ruminal pools of SP and large particles LP, a third compartment representing caecum-colon and a $T T$ including omasum, abomasum, small intestine and hind gut of $20 \mathrm{~h}$.

Other assumptions were:

- After oral ingestion, $50 \%$ of the labelled particles entering the reticulo-ruminal LP and $50 \%$ the SP pools, respectively.

- A truly indigestible fraction of $15 \%$, initially upon ingestion equally divided over LP and SP in the reticulo-rumen.

- A fracional rate of physical degradation of LP into SP of $10 \% \mathrm{~h}^{-1}$.

- A fractional rate of microbial degradation $\left(k_{\mathrm{d}}\right)$ of the LP and SP potentially degradable fraction in the reticulo-rumen of either 4 or $6 \% \mathrm{~h}^{-1}$.

- A fractional rate of passage of SP from the reticulo-rumen $\left(k_{\mathrm{p}}\right)$ of $4 \% \mathrm{~h}^{-1}$. 
- An extent of dry matter digestion in the small intestine of $14.0 \%$ of dry matter ingested.

- A $k_{\mathrm{d}}$ and $k_{\mathrm{p}}$ in the caecum-colon mixing compartment of 4 and $20 \% \mathrm{~h}^{-1}$, respectively.

- A digestion during hind gut transit of $3.7 \%$ of dry matter ingested, resulting in an overall dry matter digestion of $70 \%$.

In Figure 3, the thus simulated faecal tritium excretion curves are displayed semilogarithmicly, with tritium contained in truly and apparently indigestible faeces, respectively. The latter comprises both the faecal truly indigestible and potentially digestible fractions. This potentially digestible fraction is excreted into the faeces on top of the truly indigestible fraction, the ratio potentially digestible to truly indigestible material, with a rumen $k_{\mathrm{d}}$ of $4 \% \mathrm{~h}^{-1}$, decreasing with time from 2.8 at $t=20$ $\mathrm{h}$ to $<0.1$ at $t=100 \mathrm{~h}$. As a consequence the line describing total faecal tritium excretion is somewhat steeper as compared to the one representing the truly indigestible fraction only (for $t=60 \mathrm{~h}$ onwards $4.4 \mathrm{vs} 4.0 \% \mathrm{~h}^{-1}$ ). Assuming a rumen $k_{\mathrm{d}}$ of $6 \% \mathrm{~h}^{-1}$, this difference is even less. In that case the ratio potentially digestible to truly indigestible faecal tritium decreases from 2.8 at $t=20 \mathrm{~h}$ to $<0.1$ at $t=$ $80 \mathrm{~h}$, and the similarity of the lines describing the tritium faecal excretion curve with that of the truly indigestible fraction increases. Concomitantly a lower slope is obtained of $4.2 \% \mathrm{~h}^{-1}$, more or less resembling the slope of the curve representing the truly indigestible fraction.

Since the tritiated hay applied was highly digestible, possibly even higher than $70 \%$, a $k_{\mathrm{d}}$ of $6 \% \mathrm{~h}^{-1}$ may certainly not be excluded, justifying the conclusion that the difference in $k_{1}$ between the tritium and CrNDF faecal excretion curves cannot be caused only by the extent to which the tritium $k_{1}$ is affected by microbial

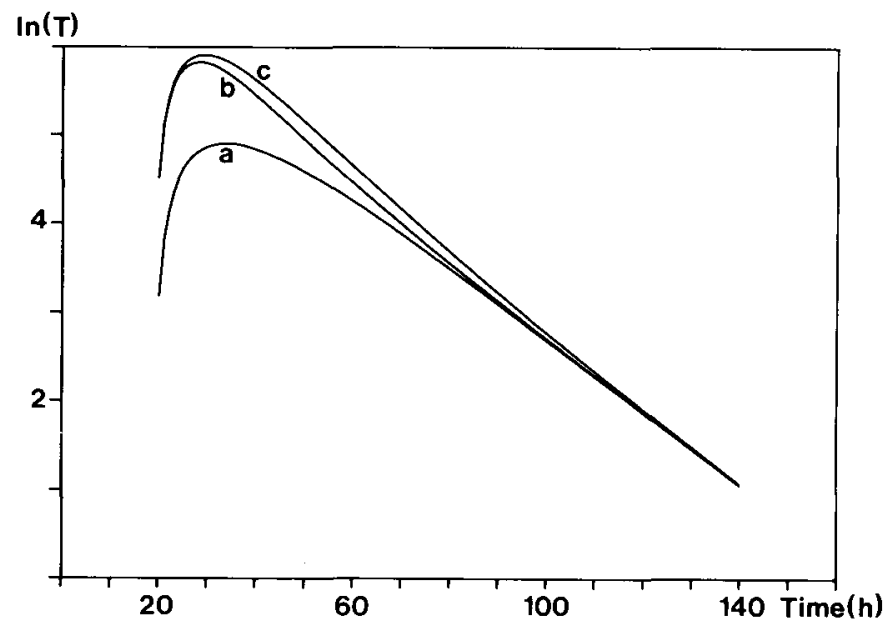

Fig. 3. The tritium label as excreted into apparently $\left(k_{\mathrm{d}}=4 \% \mathrm{~h}^{-1}\right.$ (c) and $6 \% \mathrm{~h}^{-1}$ (b)) and truly (a) indigestible faeces, plotted semi-logarithmicly (arbitrary units) against time elapsed since marker application into the reticulo-rumen. 
mobilization of tritium in the reticulo-rumen. It thus seems that in the present experiment the passage of the CrNDF particles was significantly lower than that of the tritium-labelled particles, a finding contradictory to what would be expected from the difference in functional specific gravity between CrNDF and tritiumlabelled particles as described in the introduction.

However, whether these findings apply to the highly digestible tritium-labelled hay particles only, or are applicable in a broader sense to the other feed particles as well, remains to be investigated. Nevertheless, models describing the fate of LP and SP in the reticulo-rumen emphasizing the role of reticulo-ruminal fill and particle kinetics in regulating voluntary intake of fibrous feeds by ruminants, should take the aspect into account that studies based on CrNDF may lead to biased conclusions.

\section{Acknowledgements}

The authors are gratefully indebted to Mr. D. Vink for taking care of the cannulated sheep and conducting the experiments, and to Mrs M. H. J. van den Hoek-ten Have for skilled analytical assistance.

\section{References}

Anonymous, 1983. BMDP statistical software. University of California Press, USA.

Bosch, Marlou W., I. M. Janssen, J. van Bruchem, H. Boer \& G. Hof, 1988. Digestion of alfalfa and grass silages in sheep. 1. Rates of fermentation in and passage from the reticulorumen. Netherlands Journal of Agricultural Science 36: 175-185.

Bruchem, J. van, L. J. G. M. Bongers, G. A. Bangma \& P. W. M. van Adrichem, 1987. Digestibility of amino acids in the small intestine of sheep, fed on roughage and roughage-concentrate diets. I. Herbovore nutrition research, pp. 123-124 (Ed.: Mary Rose). Australian Society of Animal Production.

Evans, E. W., G. R. Pearce, J. Burnett \& S. L. Pillinger, 1973. Changes in some physical characteristics of the digesta in the reticulorumen of cows fed once daily. British Journal of Nutrition 29: 357-376.

Faichney, G. J. \& D. A. Griffiths, 1978. Behaviour of solute and particle markers in the stomach of sheep given a concentrate diet. British Journal of Nutrition 40: 71-82.

Faichney, G. J., 1986. The kinetics of particulate matter in the rumen. In: L. P. Milligan, W. L. Grovum \& A. Dobson (Eds), Control of digestion and metabolism in ruminants, pp. 173-195. Englewood Cliffs, Prentice-Hall.

Grovum, W. L. \& V. J. Williams, 1973. Rate of passage of digesta in sheep. 4. Passage of marker through the alimentary tract and the biological relevance of rate constants derived from the changes in concentration of marker in feces. British Journal of Nutrition 30: 313-329.

Hoek, J. van den, M. H. J. ten Have \& G. B. Gerber, 1983. The metabolism of tritium and water in the lactating dairy cow. Health Physics 44: 127-133.

Hoek, J. van den, M. H. J. ten Have, G. B. Gerber \& R. Kirchmann, 1985. The transfer of tritiumlabelled organic material from grass into cow's milk. Radiation Research 103: 105-113.

Kennedy, P. M. \& D. P. Poppi, 1984. Critical particle size in sheep and cattle. In: P. M. Kennedy (Ed.), Techniques in particle size analysis of feed and digesta in ruminants, p. 170. Canadian Society of Animal Science, occasional publication No 1, Edmonton.

Sutherland, T. M., 1987. Particle separation in the forestomachs of sheep. In: A. Dobson \& Marjorie J. Dobson (Eds), Aspects of digestive physiology in ruminants, p. 43-73. Cornell University Press, Ithaca. 


\section{J. VAN BRUCHEM ET AL.}

Uden, P., P. E. Colluci \& P. J. van Soest, 1980. Investigation of chromium, cerium and cobalt as markers in digesta. Journal of Science of Food and Agriculture 31: 625-632.

Ulyatt, M. J., D. W. Dellow, A. John, C. S. W. Reid \& G. C. Waghorn, 1986. Contribution of chewing during eating and rumination to the clearance of digesta from the reticulorumen. In: L. P. Milligan, W. L. Grovum \& A. Dobson (Eds), Control of digestion and metabolism in ruminants, pp. 498-515. Englewood Cliffs, Prentice-Hall.

Waldo, D. R., L. W. Smith, E. L. Cox, B. T. Weinland \& H. L. Lucas Jr., 1971. Logarithmic normal distrubution for description of sieved forage materials. Journal of Dairy Science 54: 1465-1469.

Welch, J. G., 1986. Physical parameters of fiber affecting passage from the rumen. Journal of Dairy Science 69: 2750-2754. 